\title{
O lugar de um livro de cozinha em uma biblioteca pública renascentista: estudo sobre o De re coquinaria, atribuído a Apício, a partir do manuscrito laurenziano Plut. 73.201
}

The place of a cookbook in a Renaissance public library: study on Apicius' De re coquinaria from the Laurentian manuscript Plut. 73.20

\author{
WANESSA ASFORA NADLER ${ }^{2}$ \\ Universidade Estadual de Campinas / Campinas, SP, Brasil
}

RESUMO: Alguns dos primeiros manuscritos renascentistas do livro de cozinha atribuído a Apício, produzidos na segunda metade do século XV, foram quase certamente confeccionados para integrar coleções de bibliotecas privadas de poderosos senhores de cidades da Itália do Norte e Central. Entretanto, a história de um deles, o manuscrito laurenziano Plut. 73.20 - transladado da coleção privada dos Médici para a primeira biblioteca pública moderna, a Biblioteca Medicea Laurenziana - permite uma reflexão mais ampliada. A partir da observação de aspectos materiais do manuscrito, bem como daqueles referentes à história de seu armazenamento espacial, desenvolve-se uma reflexão acerca de como os conteúdos de Apício foram interpretados e classificados pelos humanistas da época. A hipótese perseguida é que os humanistas, particularmente aqueles interessados em medicina, exerceram um papel importante na transformação do livro de cozinha apiciano, que passa a ser, ao menos durante um certo período de tempo, classificado como médico e não culinário.

PALAVRAS-CHAVE: Apício. Renascimento italiano. Livros de cozinha. Medicina. Bibliotecas. Circulação de conhecimento.

ABSTRACT: Some of the first Renaissance manuscripts of the cookbook attributed to Apicius, produced in the second half of the $15^{\text {th }}$ century, were almost certainly made to integrate private

\begin{abstract}
1. A pesquisa que originou este artigo se insere no projeto de pós-doutorado "Apício nos séculos XV e XVI: manuscritos, livros e circulação de saberes médico-culinários", conduzido no âmbito do Departamento de História da Universidade Estadual de Campinas (Unicamp), sob supervisão da Profa. Dra. Leila Mezan Algranti e com financiamento da Fundação de Amparo à Pesquisa do Estado de São Paulo (Fapesp). Uma versão preliminar do texto foi apresentada no II Seminário Internacional de História da Alimentação e Cultura Material: circulação de artefatos, saberes e fazeres, realizado em Campinas (SP), entre $3 \mathrm{e}$ 5 de maio de 2017.
\end{abstract}

2. Pesquisadora de pós-doutorado na Unicamp e bolsista de pós-doutorado da Fundação de Amparo à Pesquisa do Estado de São Paulo (Fapesp). E-mail: <wanasfora@gmail.com> 
3. Trata-se do texto canônico constituído por 459 receitas distribuídas ao longo de dez livros, que orientam a preparação de bebidas, conservas, carnes vermelhas, aves, peixes, frutos do mar, massas, legumes, grãos, dentre outras. Existe ainda um texto mais curto, os Excerpta, que apresenta uma única lista de 31 receitas. Cf. Grainger; Grocock (2006).

4. Uma lista completa de fontes antigas e medievais que fazem referência a Apício se encontra em André (1987, p. xxv-xxix); Grainger; Grocock (2006, p. 363-368).

5. Bilabel (1920, p. 27-28).

6. São eles: o Lat. 10318, arquivado na Bibliothèque Nationale de France, de origem discutível, mas provavelmente escrito no sul da França ou norte da Itália e datado dos últimos anos do século VIII e/ou início do IX); Nova York, New York Academy of Medicine 1 (originário da abadia de Fulda e datado da primeira metade do século IX); e o Urb. Lat. 1146, na Biblioteca Apostólica Vaticana, produzido na igreja colegial de Saint Martin de Tours, provavelmente entre os anos de 830 e 853. (Milham, 1967, p. 262-265).

7. Cf. Asfora (2014).

8. Cf. Firenze Biblioteca Medicea Laurenziana (14581464); Firenze, Biblioteca Medicea Laurenziana, Strozzi 67 (segunda metade do século XV); Firenze, Biblioteca Riccardiana, 141 (segunda metade do s. XV); Firenze, Biblioteca Riccardiana, 662 (1464); Biblioteca Apostólica Vaticana (1494, 1483-1489); Cesena, Biblioteca Malatestiana, 167, 154 (século XV); Paris, Bibliothèque Nationale 8209 (século XV); São Petesburgo, Instituta Istorii Akademii libraries of powerful signori of Northern and Central Italy. Nonetheless, the long history of the Apician manuscript Plut. 73.20 - an item that was moved from the Medici's private collection to the first modern public library in Florence, the Biblioteca Medicea Laurenziana - allows further considerations about it. The investigation of its material aspects, as well as of its physical and spatial location in the library, will be used in this article as a starting point to discuss how the contents of Apicius' cookbook were interpreted and classified by the humanists of its time. The working hypothesis is that humanists, particularly those interested in medicine, were fundamental in changing its classification, at least temporarily, from culinary to medical one.

KEYWORDS: Apicius. Italian Renaissance. Cookbooks. Medicine. Libraries. Circulation of knowledge.

\section{INTRODUÇÃO}

- livro de cozinha atribuído a Apício, usualmente conhecido por De re coquinaria, é uma compilação de receitas médico-culinárias advindas de diferentes períodos do contexto romano imperial. ${ }^{3}$ Não são poucas as referências à obra e ao seu suposto autor - um gastrônomo que teria vivido na Roma do primeiro século da era cristã - encontradas ao longo de fontes antigas e altomedievais. ${ }^{4}$ Nelas Apício e seu texto se fundem e se confundem, transformando-se na autoridade mais célebre que nos deixou o mundo antigo quando o assunto é cozinha. No entanto, a história do texto apiciano, nos suportes manuscrito e impresso, permanece ainda pouco conhecida e estudada. À parte um pequeno fragmento em papiro, ${ }^{5}$ três manuscritos carolíngios, produzidos entre os séculos VIII e IX em diferentes localidades do ocidente europeu (França, Alemanha e possivelmente Itália), constituem os registros escritos completos mais antigos de que se tem notícia. ${ }^{6}$ A existência altomedieval do texto apiciano parece ter sido pontual e circunscrita a um dado grupo social marcado pelas aspirações do Renascimento Carolíngio.? Ao que tudo indica, após esse momento, um grande silêncio envolveu o texto, que voltou a receber atenção apenas muito posteriormente. Na segunda metade do século XV, impulsionados pelo interesse de alguns humanistas italianos, os manuscritos medievais de Apício foram postos novamente em circulação, e indícios de uma releitura de seus conteúdos podem ser evidenciados, por exemplo, pelas dezesseis cópias manuscritas produzidas naquele período ${ }^{8}$ e cinco edições subsequentes, impressas nos últimos anos do século XV e na primeira metade do XVI. ${ }^{9}$ 
manuscrito Plut. 73.20 encontra-se atualmente na Biblioteca Medicea Laurenziana, em Florença. ${ }^{10}$ Foi confeccionado em pergaminho e mede aproximadamente $150 \mathrm{~mm} \times 220 \mathrm{~mm}$. $\bigcirc$ códice que o contém possui encadernação em couro marroquino vermelho com impressão a frio das armas dos Médici em um brasão central, bem como nas ponteiras de ferro. Ali está também a indicação de sua cota. Trata-se de uma encadernação do século XVI, posterior à sua confecção, que é da segunda metade do século XV, como veremos logo adiante.

$\bigcirc$ receituário de Apício não está sozinho no códice. Nos 82 fólios encontram-se as seguintes obras, nesta ordem: Apício (ff. 1r-46r); a Gêrmania de Tácito (C. Cornelii Taciti equitis, De origine et situ Germaniae liber (ff. 46r-6 1r); e quarenta e sete cartas de Diógenes, o filósofo cínico de Sínope, traduzidas para - latim pelo humanista Francesco Aretino Griffolini e dedicadas ao papa Pio II Iff. 61 v-82). Tal dedicatória tem sido comumente usada como referência para datar o códice que teria, com isso, sido produzido em algum momento entre 1458 e 1464, período do papado de Pio II. ${ }^{11}$

primeiro fólio existente do texto de Apício foi escrito em littera antiqua. ${ }^{12}$ A decoração é refinada: uma borda com vinhas que se entrelaçam e onde se acham putti, pássaros, um retrato humano não identificado ${ }^{13}$ e o brasão dos Médici. Nos demais fólios há menos suntuosidade, mas aparecem capitais decoradas em vermelho, azul, verde e ouro no início de cada capítulo. Voltando ao primeiro fólio, encontramos o brasão dos Médici na borda inferior. A presença de anotações marginais é rara em todo o manuscrito e limita-se a algumas correções do latim.

A ligação com os Médici evidencia-se não apenas pelo brasão, mas também pelos profissionais envolvidos com a confecção do manuscrito de Apício. Tanto o copista, identificado como Messer Piero di Benedeto Strozzi (c. 1416-1492?), ${ }^{14}$ quanto o decorador, cujo nome é desconhecido, foram pessoas do círculo de Vespasiano da Bisticci (1421-1498), bibliófilo e negociante de livros muito célebre e ativo no XV, e bastante próximo dos Médici. Se é certo que o manuscrito foi produzido para a coleção privada da família Médici, não se pode afirmar o mesmo sobre quem teria sido seu destinatário: Cósimo de Médici (1 389-1464) ou um de seus filhos, Piero 1416 1469) e Giovanni (1421-1463). Há, porém, indícios apontando para o último, pois na época da sua confecção, Vespasiano andara trabalhando como intermediário na produção de uma série de manuscritos de luxo, muitos deles
Nauk 627/2 (1490-93); São Petesburgo, Instituta Istorii Akademii Nauk 627/1 (século XV ou após 1465); Oxford, Bodleian Library, Canonicianus Class. Lat. 168 (1490); Oxford, Bodleian Library, Add. B 110 (segunda metade do século XV); Copenhagen, The Royal Danishn Library, Sammlung 3553 (1479); Munique, clm 756 (c.1495). Muito recentemente identificamos na base de dados Manus um manuscrito de Apício nunca antes mencionado pelos especialistas (Cf. Biblioteca Estense Universitaria). O texto está em fragmentos e necessita ser estudado na sua relação com outras cópias do stemma filológico.

9. Cf. Rothmagensem (1498); Venetum (1500); Tacuinum (1503); Torinus (1541); Hummelberg (1542).

10. O manuscrito está digitalizado e pode ser visualizado no site da Biblioteca Medicea Laurenziana, $<$ https://bit.ly/2MsPgvm>.

11. Milham (1967, p. 266).

12. Tratava-se de um tipo de letra inspirada na minúscula carolíngia, que havia ficado em moda com Petrarca e Niccolò Niccoli, usada a princípio apenas por um grupo seleto de humanistas e bibliófilos que imaginavam, por meio dela, conseguir apresentar os textos antigos sob uma aparência mais próxima de seu aspecto original, distinto dos exemplares produzidos na Idade Média (Febvre; Martin, 1992, p. 119-120).

13. Já foi aventada a possibilidade de se tratar da efígie de Apício (Cf. Bandini, 1774-1777), porém, tal hipótese nunca foi comprovada.

14. Apesar de ter assinado poucos manuscritos, especialistas identificaram mais 
de setenta documentos, produzidos entre $1443 \mathrm{e}$ $1485 / 1490$, total ou parcialmente atribuídos a ele. Messer Piero de Benedetto Strozzi, pároco de Ripoli, era próximo de Vespasiano da Bisticci, que escreveu um relato sobre ele na vida de seu pai, Benedetto Strozzi. Ali o chamou de "o mais belo escriba de seu tempo e o mais acurado". A maior parte de seus manuscritos foram copiados para clientes conhecidos de Vespasiano, nos primeiros tempos majoritariamente para os Médici e, mais tarde, para várias coleções reais em Nápoles. (De la Mare; Garzelli, 1985, p. 430-431).

15. Ao que tudo indica, os irmãos Piero e Giovanni competiam na formação de suas bibliotecas. Segundo Albinia de la Mare (1996, p. 183-185), Giovanni parece ter sido o mais discriminatório tanto na seleção dos textos quanto na escolha dos copistas e iluminadores, mas Piero levava vantagem sobre ele, pois tinha ficado com a biblioteca de seu pai em c. 1450.

16. Apesar da iniciativa, Cósimo, ao longo de sua vida, esteve muito mais envolvido com o projeto de estabelecimento de uma biblioteca pública em Florença, o que se concretizou oficialmente apenas em 1441, com sua fundação no Convento de San Marco. O edifício projetado por Michelozzo, porém, abriu as portas ao público efetivamente apenas em 1444 (Ciapelli, 2001, p. 429-431).

17. A obra não figura em nenhum dos inventários anteriores de bens da família Médici; não consta dos 63 livros listados no inventário de Cósimo, composto nos primeiros anos da constituição de cópias de textos clássicos, para Giovanni de Médici lcuriosamente, o pavão utilizado na decoração do primeiro fólio do texto apiciano costumava ser uma marca de Giovanni). ${ }^{15}$ Além disso, como se verá a seguir, dos três Médici mencionados, Giovanni é o único que aparece na documentação como alguém bastante empenhado em adquirir um conjunto de manuscritos medievais recém encontrados, dentre os quais estavam os de Apício. Contudo, neste artigo não avançaremos nessa direção por falta de evidências mais concretas.

\section{APÍCIO E A MEDICEA PRIVATA}

De uma forma ou de outra, a história desse manuscrito de Apício é reconhecidamente parte da coleção de livros particular dos Médici, também chamada Medicea Privata, iniciada por Cósimo, o velho, por volta de 1410.16 No entanto, não se sabe exatamente quando o manuscrito entrou para aquela coleção. ${ }^{17} \bigcirc$ primeiro registro concreto é da época de Lorenzo, o magnífico 11449 1492), herdeiro de um patrimônio de cerca de oitocentos livros acumulados desde os tempos de seu avô Cósimo. ${ }^{18}$ No registro de empréstimo de seus bens há uma referência do ano de 1480 a um empréstimo do códice inteiro para Bernardo Rucellai (1448-1514), uma figura importante envolvida com a Academia Platônica de Florença e também cunhado de Lorenzo. Rucellai permaneceu com o manuscrito por dois anos (até 5 de novembro de 1482). ${ }^{19}$

Antes de 1480, o que se sabe é que a família, ou pelo menos Giovanni de Médici, já havia demonstrado interesse e empenho em obter Apício. Através da correspondência de Giovanni, conseguimos acompanhar um pouco dessa história. Em 1455 o humanista Enoch d'Ascoli havia chegado em Roma carregado de alguns manuscritos medievais adquiridos em mosteiros da França e da Alemanha, inclusive o de Apício. Giovanni, que estava em Florença, pediu então que seu irmão ilegítimo, o sacerdote Carlo de Médici, (1428/30-1492) intermediasse o acesso a eles. Em 1456 Carlo escreve a Giovanni dando notícias dos manuscritos, mas explicando que Enoch estava cobrando muito caro pela permissão para copiar aquilo que, na sua opinião, valia mais pela novidade do que pela utilidade. ${ }^{20}$ Giovanni não desistiu e tentou adquirir os manuscritos de Enoch por outras vias. Um ano depois, seu primo, o banqueiro Pierfrancesco di Lorenzo de Médici 1 14301476), the escreveu dizendo que do conjunto trazido por Enoch talvez ele conseguisse apenas Apício, pois os demais já haviam sido incorporados à coleção papal. ${ }^{21}$ No início de 1458 Giovanni seguia em sua busca, mas, ao que tudo indica, o acesso a Apício ou a qualquer outro manuscrito trazido por Enoch 
inviabilizou-se com seu desparecimento e sua posterior morte. Nem mesmo o envio por Carlo de Médici de um pedido de ajuda para recuperar os manuscritos, ou cópias deles, ao governador do Marche, onde havia morrido Enoch, foi capaz de pôr fim à questão. ${ }^{22}$ Diante disso, Giovanni talvez tenha desistido da busca ou talvez tenha simplesmente mudado de ideia. Concretamente, o que se pode afirmar é que os Médici acabaram por adquirir sua cópia do texto apiciano, o manuscrito Plut. 73.20, a partir de um apócrifo descendente de outro manuscrito medieval que não aquele trazido por Enoch.

Mas voltemos à Lorenzo e ao período do primeiro registro do manuscrito na Medicea Privata. Com sua morte, os livros de Lorenzo foram herdados pelo filho, Piero, o Desafortunado (1471-1503). Dois anos após o início de seu governo, em 1494, Piero se rendeu incondicionalmente diante da invasão do rei da França, Carlos VIII (1470-1498), que atravessou Florença com seu exército, descendo em direção a Nápoles. ${ }^{23} \mathrm{Na}$ ocasião, todos os bens dos Médici foram confiscados pela Signoria de Florença, e os livros da coleção privada, por questões de segurança, depositados no Convento de San Marco, onde já funcionava, como dissemos, a biblioteca pública da cidade. $\bigcirc$ inventário de 1495 foi compilado pelo bibliotecário de Lorenzo Giano Lascaris e pelo chanceler Bartolomeo Ciai justamente nesse momento crítico. A coleção inventariada continha 1017 códices, 688 dos quais foram distribuídos em dezessete caixas. Apício estava na segunda caixa e levava o número $618 .{ }^{24}$

A partir daí, tem início a itinerância de Apício. $\bigcirc$ livro que sempre havia estado em salas privadas localizadas na suntuosa residência dos Médici no centro de Florença, passou a perambular entre alguns estabelecimentos ao sabor dos revezes políticos pelos quais atravessava a cidade naquele final de século. Do Convento de San Marco seguiu para a Badia Beneditina de Florença e de lá, em 1500, de volta a San Marco. ${ }^{25}$ Oito anos depois, o cardeal Giovanni de Médici, filho de Piero (e o papa Leão X, a partir de 1513), demonstrou interesse nos livros da família e levou-os para Roma, após pagar a substancial quantia de 2600 ducados, onde permaneceram no atual Palazzo Madama até sua morte, em 152 1. ${ }^{26}$ Em 1523, com receio de confisco da coleção para a Biblioteca Vaticana, os livros foram enviados novamente para Florença por seu primo Giuliano (futuro papa Clemente VII) e mantidos em caixas na residência dos Médici até 1527. Com uma nova expulsão dos Médici de Florença, ${ }^{27}$ os livros foram removidos para o refeitório do Convento de San Lorenzo onde permaneceram até sua transferência definitiva para o edifício da atual Biblioteca Medicea Laurenziana aberta ao público em 1571,28 no governo de Cósimo I (1519-1574), grão-duque da Toscana, onde permanecem até hoje. Esse momento põe término à itinerância do sua coleção, entre 1417 1418 (Pintor, 1960, p. 197 199; De la Mare, 1992, p. 115-156), tampouco aparece dentre os 158 livros de seu filho Piero, listados em dois inventários, diferentes compostos em 1456 e 1465 , respectivamente (Piccolomini, 1875, p. 106 112; Ames-Lewis, 1982, p. 118-131; 132-142).

18. Com Lorenzo, a Medicea Privata aumentará significativamente, embora seja difícil precisar "quanto e com que ritmo as várias gerações de Médic fizeram acréscimos a 'libreria' da via Larga”. Segundo Ciapelli (2001, p. 433), Cósimo teria sido responsável por cerca de 150 volumes. Na época da morte de Piero, seu filho, foram reunidos provavelmente trezentos. Lorenzo teria adquirido cerca de oitocentos. Assim, a Medi cea Privata, à morte de Lorenzo, possuía pouco mais de 1100 volumes, quase todos manuscritos.

19. “A Girolamo de' Ross da Pistoia, sta qui pe'Martini da Vinegia, a requisitione di Bernardo Rucellai, si prestò a dì 24 di gennaio, de' libri di Lorenzo: Apitio, Cornelio Tacito de situ Germanie et l'Epistole di Diogene insieme, di mano di messe Piero Strozzi, coperte verde. Renduto a di 5 de novembre 1482." (Ricordi di arenti... 1956, p. 227-228).

20. "Egli è vero che $\mathrm{m}$ Enoche ha portato qui certe cose nuove, come vedrete per questo inventario vi mando ed invero da farne più stima per la novità che per la utilità. Lui per insino a qui non ha volute farne copia a persona, imperò dice non vuole avere durate fatiche per altri e non delibera darne copia alcuna, se prima da qualche grande maestro no è remunerato degnamente ed ha 
oppenione d'averne almanco 200 o 300 fiorini, sì che vedete se volete gettare via tanti danari per cose che la lingua latina può molto bene fare senza esse, che a dirvi l'oppenione di molti dotti uomini, che gli ànno visti, da questi quattro infuori che sono segnati con questo segno $\mathrm{X}$, tutto il resto non vale una frulla" (13 de março de 1456) (Archivio di Stato, M.A.P. Filza 9:135 apud Milham, 1967, p. 291).

21. "De'libri mi scrivete farò ogni diligentia perchè n'abiate copia et maxime di quello Apicio, che credo sarà più facile avere che gli altri, perchè gli à avuti il papa [...]" (Roma, 1457) (Archivio di Stato, M.A.P. Filza 137, 86 apud Milham, 1967, p. 291).

22. "Per una vostra sono avisato come aveste la lettera mi scrisse m. Stephano de Nardinis supra quelli libri di Enoc; non ho poi altro, ma non dubitate che per essere il primo che gl'abbia, non v'ànno a costare uno denaro di più" (Roma, 13 de janeiro de 1458) (Archivio di Stato, M.A.P. Filza 9, 576 apud Milham 1967, p. 292).

23. O episódio faz parte das chamadas Guerras da Itália, uma sequência de conflitos pelo poder que envolveram, ao longo dos últimos anos do século XV e início do XVI, o Sacro Império Romano Germânico, o Reino da França, então aliado dos Estados Pontifícios, algumas cidades-Estados italianas e a Espanha. A participação de Florença e dos Médici nos conflitos acabou resultando em duas expulsões da família da cidade (1494 e 1527).

24. "618. Apicius, in membranis, latinus, in volumine parvo e viridi. - Lat." (Filza 87 Archivio Mediceo manuscrito de Apício, que acabou acorrentado a um dos 88 bancos da biblioteca (os chamados pluteil.

Os bancos - executados pelos entalhadores Giovan Battista del Cinque e Ciapino, seguindo desenho de Michelangelo - tinham dupla função: leitura e custódia. Na sua parte interna, os livros, todos tendo recebido novas encadernações em couro marroquino vermelho e correntes de ferro lque podemos apreciar ainda hoje), foram guardados em posição horizontal, ordenados segundo a classificação de saberes vigentes na época. ${ }^{29}$ A lateral de cada pluteo contém uma inscrição indicativa da seção temática à qual aquele banco pertence e uma tabuleta com o elenco de obras que armazena, conforme se observa na Figura 1.30

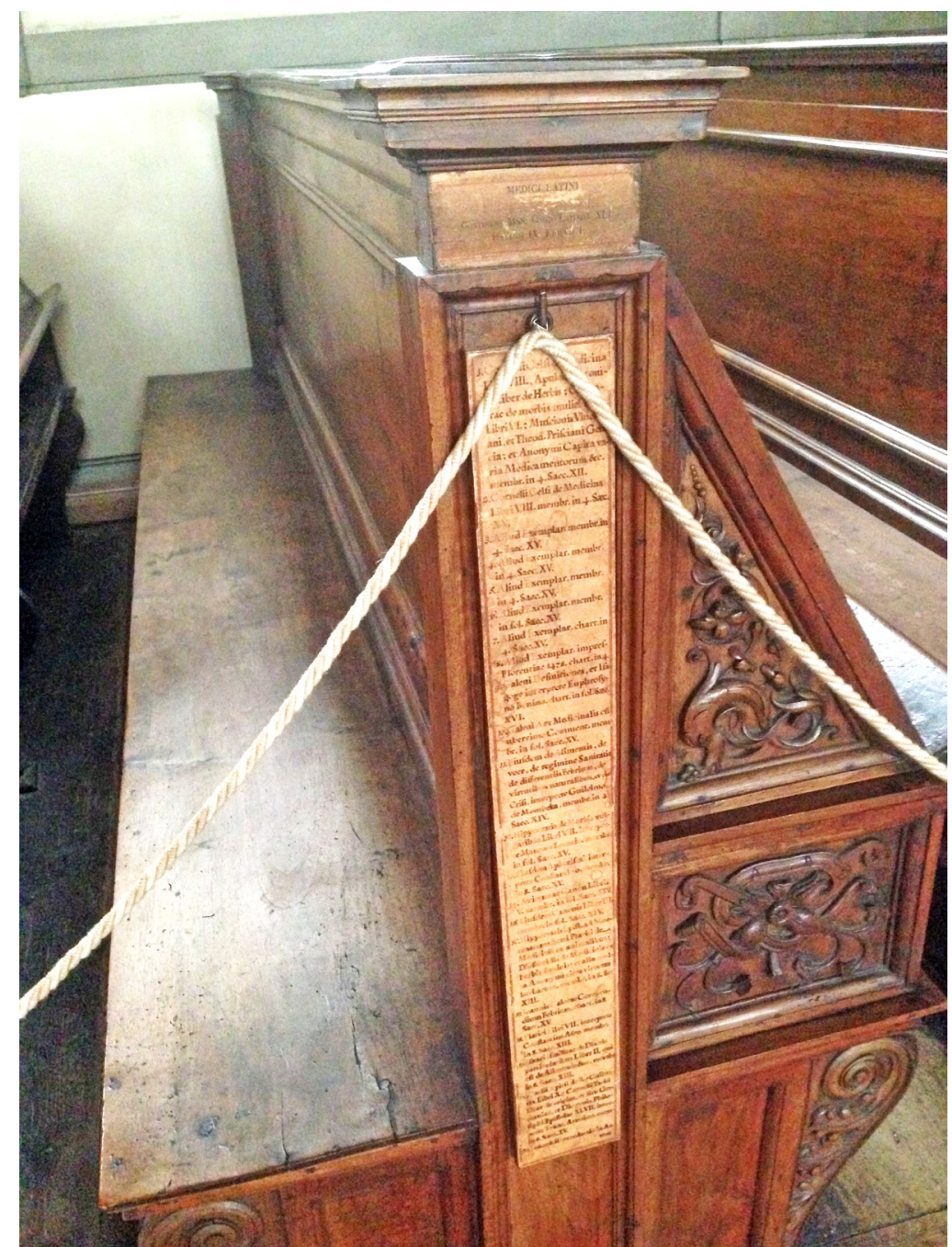

Figura 1 - Pluteo 73, 2015. Fotografia do autor. 
número de chamada de Apício provém exatamente da sua localização física e espacial dentro da biblioteca. Plut. 73.20 indica que Apício pertencia ao banco 73 e era o item de número 20 da lista de obras ali contidas. A Figura 2 mostra a lateral superior do banco, onde se encontra a inscrição "MEDICl LATINI/CONTIENS MSS CODD. LATINOS XLI/ITALICOS IX EDITUM I", que faz referência à seção de textos médicos latinos disposta ao longo dos bancos 73 e 75. A inscrição, réplica da original do século XVI, alude acertadamente ao conjunto de obras médicas recebidas da coleção particular dos Médici. Já a tabuleta enumera daquele conjunto vinte textos latinos (em manuscritos datados do século XIII ao XV) de autoria atribuída a autores antigos gregos, latinos e árabes, como Hipócrates, Galeno, Dioscórides, Celio Aureliano, Apuleio, Cornélio Celso, Isaac Israeli e Avicena. A Figura 3 destaca a referência a Apício inscrita na parte final da tabuleta.

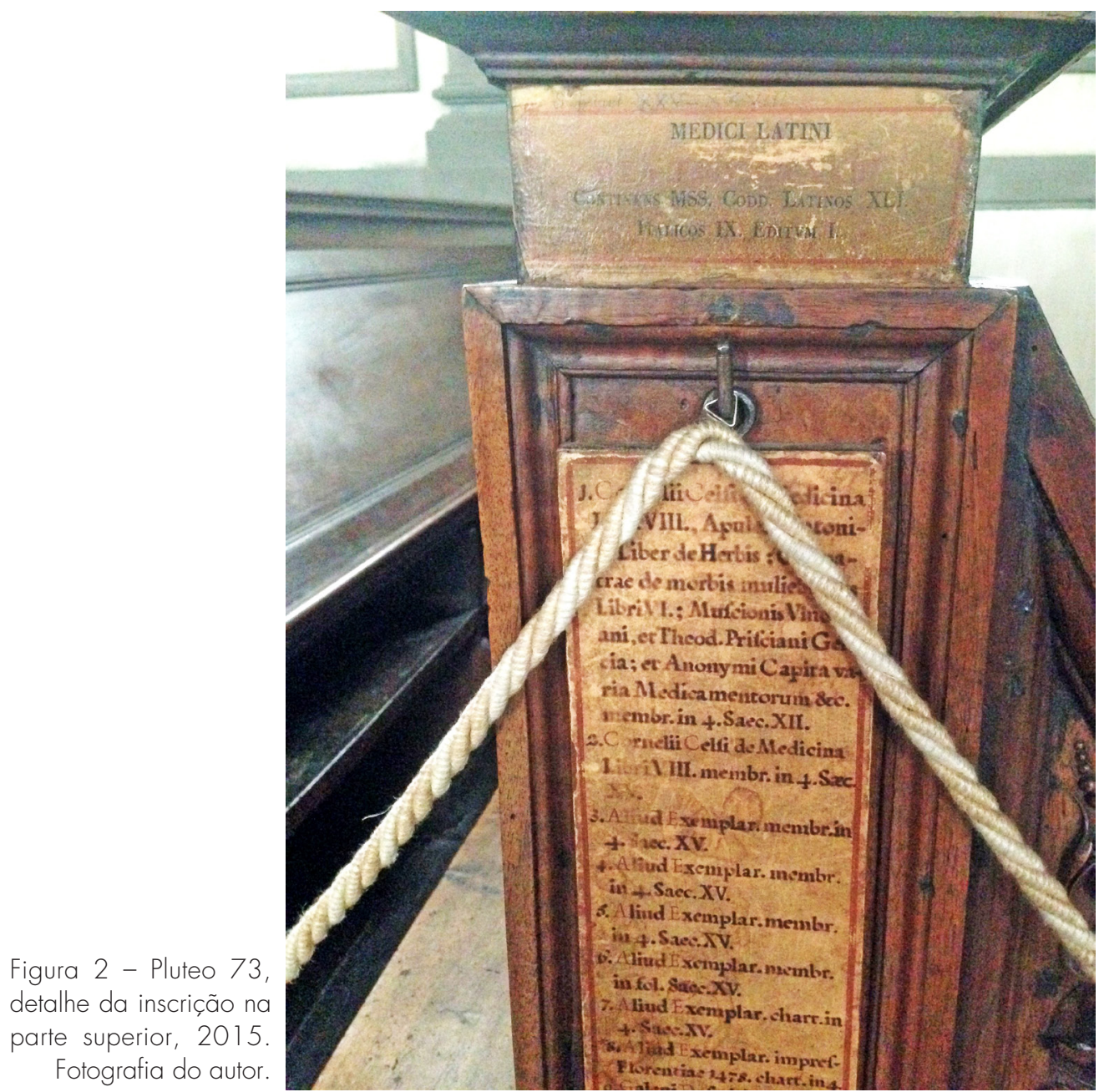

Avanti il Principato). Editado em Piccolomini (1875, p. 65-108).

25. Em 19 de outubro de 1495, a Signoria pede um empréstimo de 2000 florins a San Marco, deixando os livros como garantia. Mais tarde, por não conseguir honrar o empréstimo, a Signoria propõe que San Marco fique com os livros - avaliados em 3000 florins - e lhe pague a diferença de 1000. Em 18 de abril de 1498 , o convento de San Marco sofre um ataque por parte de opositores de seu prior, Girolamo Savonarola. Embora os livros não tivessem sido danificados, o acontecimento convence a Signoria de os vender ao Palazzo Vecchio. A venda aconteceu em 12 de dezembro de 1498 e após um tempo na Badia Beneditina em Florença, os livros voltaram a San Marco em setembro de 1500 (Stam, 2001, p. 399).

26. Stam (2001, p. 399).

27. Cf. nota 23.

28. A Biblioteca Medicea Laurenziana foi concebida por Lorenzo de Médici e concretizada por seu sobrinho Giulio de Médici, papa Clemente VII, a partir de 1523 , segundo projeto de Michelangelo Buonarotti (1475-1564). A obra, que teve início em 1524, foi interrompida em 1534, ano da partida de Michelangelo de Florença e da morte daquele papa. O projeto foi retomado posteriormente no ducado de Cósimo I (1519-1574) e a biblioteca foi finalmente aberta ao público em 1571. O edifício seiscentista ocupa uma parte do Convento de San Lorenzo e funciona atualmente apenas como biblioteca monumental. O acervo original foi transferido para um espaço no piso superior do claustro do mesmo 
convento. Disponível em: <https://bit.ly/2MlQoRj>.

29. Segundo o site da Biblioteca Medicea Laurenziana, essa disposição organizacional foi mantida até o início do século $\mathrm{XX}$, quando então os manuscritos foram transferidos para o atual espaço da biblioteca. Já os livros impressos, em 1783 foram entregues aos cuidados da Biblioteca Magliabechiana, hoje na Biblioteca Nacional Central de Firenze. Disponível em: <https:// bit.ly/2MlQoRj>.

30. O que se vê hoje na Biblioteca Laurenziana são reproduções dos originais do século XVI: as inscrições foram confeccionadas no século XIX e as tabuletas, no século XVIII (Rao, 2012, p. xvi e xvii).

\section{Confaurino Airo. memo:} in 8. Sacc.X111.

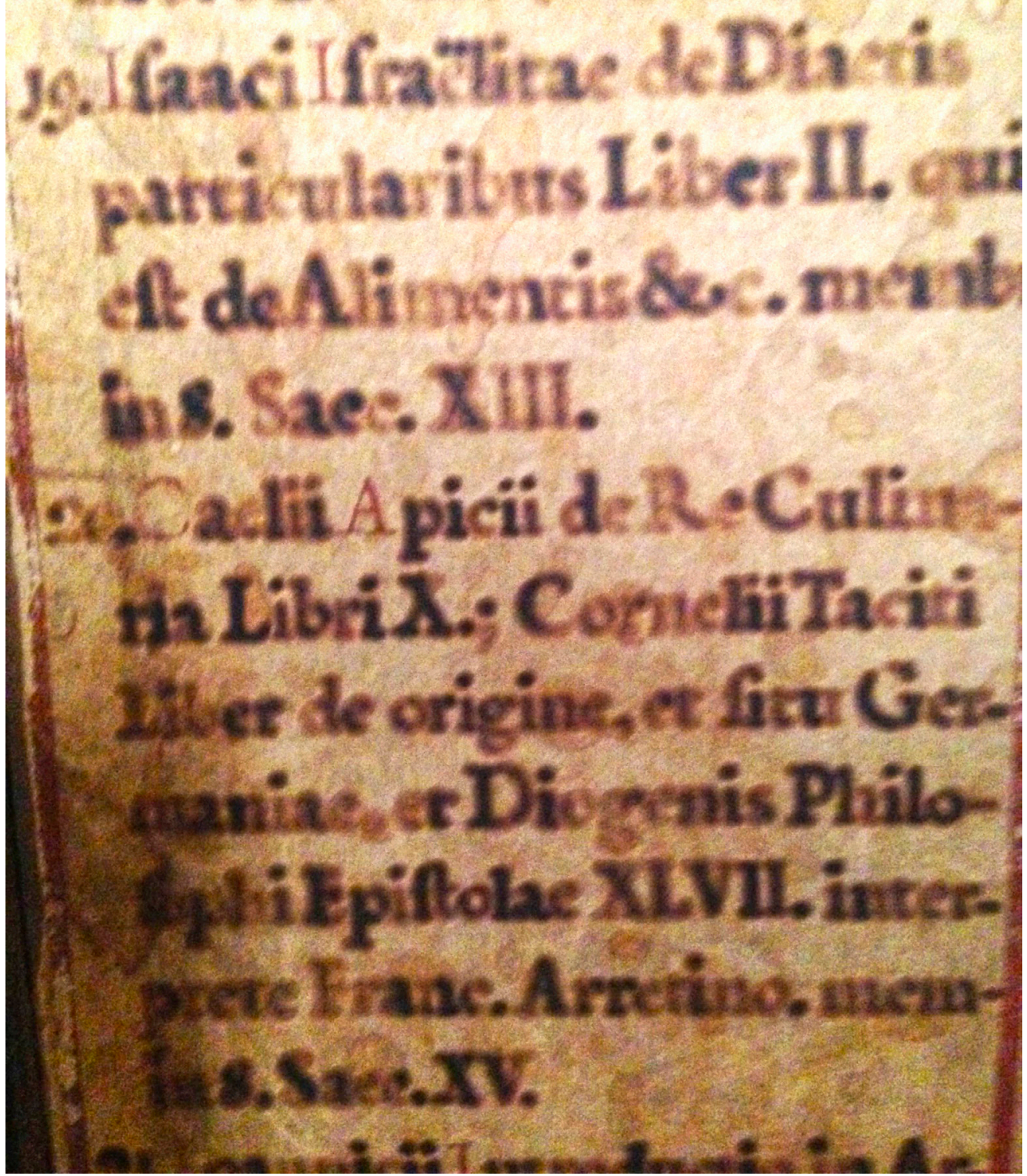

Figura 3 - Pluteo 73, referência a Apício (item n² 20 da tabuleta), 2015. Fotografia do autor.

O célebre livro de cozinha romano, assim, encontrou lugar na coleção de obras médicas. $\bigcirc$ que pode parecer apenas um detalhe - já que passou desapercebido pelos estudiosos da Apiciana - é, ao contrário, um indício importante para a reflexão acerca da trajetória, sentido e recepção de Apício no Renascimento. 


\section{DESLOCAMENTO ESPACIAL E DE SENTIDO NO USO E NA LEITURA DE APÍCIO}

Na trajetória do manuscrito Plut. 73.20 é possível identificar três momentos em que se particularizam elementos relativos à natureza da coleção à qual esteve atrelado (e, nesta, sua localização e armazenamento), bem como à função e ao significado que ali desempenhou. Embora entendamos não se tratar de momentos estanques e tão nitidamente distinguíveis - há certamente zonas de superposição entre eles -, elaboramos o Quadro 1 para ressaltar a predominância de certos

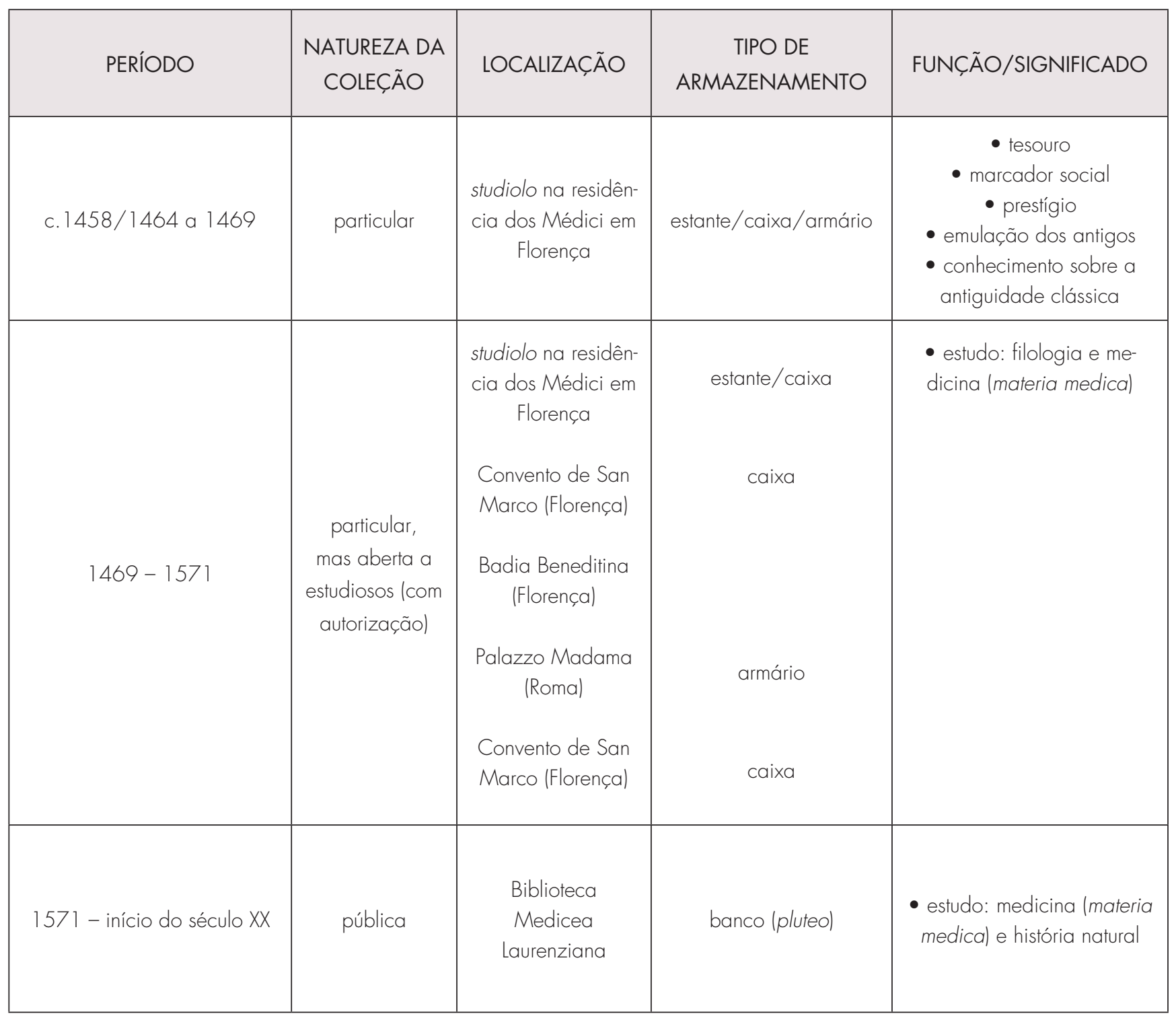


31. Bouza-Alvarez (2001); Burke (1997, 1998); Chartier (1996, 2007, 2009); Cavallo (1989, 1994).

32. O termo em italiano para designar esse espaço específico parece ter variado um pouco na documentação: scriptoio, nos tempos de Cósimo, o velho, e studietto nos tempos de Piero de Médici (Rao, 2012, p. xix-xx). Sobre a interação entre objetos e o espaço do studiolo no Renascimento, cf. Clark (2013).

33. Ciapelli (2001, p. 435).

34. Piccolomini (1875); Pintor (1960). traços característicos da existência do manuscrito naquela trajetória. As categorias "função" e "significado" escolhidas para análise procuram dar conta, em menor escala, da expressão de necessidades de certos grupos sociais e, de maneira mais contundente, das formas de expressão de práticas e representações culturais daqueles mesmos grupos. Isso significa que, do ponto de vista teórico, nossa análise se alinha a uma história cultural da circulação e reprodução dos manuscritos e dos livros. ${ }^{31}$

\section{Tesouro}

O primeiro momento, como vimos, é o tempo em que o manuscrito pertenceu à coleção pessoal da família Médici; estender-se-ia da época de sua encomenda e confecção, entre 1458 e 1464, até o final de governo de Piero de Médici, em 1469. Durante esse curto período, a obra permaneceu abrigada em estantes, caixas ou armários encerrados em um studiolo, espaço destinado ao estudo, mas também à exibição de objetos pessoais da residência dos Médici. ${ }^{32}$

As características materiais do manuscrito de Apício - pergaminho, rica decoração e quase ausência total de comentários marginais feitos por leitores/ usuários -, diferentemente de outros manuscritos apicianos que não possuem decoração, foram escritos em papel e/ou possuem uma quantidade maior de comentários em suas margens, indicariam uma função muito mais ostentatória do que prática. Seja no studiolo de Giovanni ou no de Lorenzo, Apício seria uma espécie de peça de coleção, um tesouro, embelezando aquele espaço privado e transformando-o em vitrine que sinalizava a distinção social possibilitada pelas posses e pelo mecenato que os Médici exerciam em Florença. É importante lembrar que aqueles foram anos decisivos para a afirmação de poder da família Médici na direção política e econômica de Florença contra as oligarquias republicanas ou nobiliárquicas de tradição medieval. ${ }^{33}$

Ademais, a ideia de Apício como tesouro está ancorada não apenas no valor estético do manuscrito em si, mas igualmente naquilo que poderia evocar. A biblioteca renascentista ideal era aquela construída sobre os preceitos dos estudos humanísticos, segundo o Cânone Bibliográfico compilado por Tommaso Parentucelli (1 397- 1455), futuro Papa Nicolau V - o papa que havia enviado Enoch d'Ascoli à caça de manuscritos medievais. $\bigcirc$ Cânone foi encomendado por Cósimo de Médici quando de seu envolvimento com a organização das bibliotecas públicas de San Marco e da Badia di Fiesole. Mais tarde foi usado por aquele mesmo papa na organização da Biblioteca Vaticana e de outras bibliotecas públicas e privadas do período. ${ }^{34}$ Pode ser definido como a lista de livros essenciais que qualquer biblioteca humanística 
que se quisesse completa deveria conter. Concretamente, isso significava pais da Igreja e outros autores cristãos, juntamente com obras laicas da antiguidade grecolatina. No entanto, a lista não incluía vários outros autores que se sabe constarem regularmente das coleções de bibliotecas humanísticas do Renascimento italiano no período. ${ }^{35}$ Apício não aparece elencado no Cânone le, diga-se de passagem, nenhum outro receituário médico ou culinário), ${ }^{36}$ mas as não poucas referências a ele encontradas em Sêneca, Plínio, Marcial e Juvenal, por exemplo, ${ }^{37}$ teriam certamente servido para suscitar o interesse em sua aquisição.

É oportuno lembrar, ainda, que razões semelhantes parecem ter motivado outros senhores italianos, além dos Médici, a adquirir manuscritos de luxo de Apício para suas coleções particulares. Do conjunto de manuscritos renascimentais, é possível identificar inicialmente os Strozzi de Florença e os Rossi de Bolonha como proprietários de manuscritos apicianos (respectivamente, Florença, Biblioteca Medicea Laurenzia, Strozzi 67 e Oxford, Bodleian Library, Canonicianus Class. Lat. 1681. ${ }^{38}$ A esses nomes devemos acrescentar o de Federico de Montefeltro, Duque de Urbino, que em vez de encomendar uma cópia coetânea de Apício para sua biblioteca, adquiriu o mais luxuoso dos manuscritos carolíngios existentes. ${ }^{39}$

$\bigcirc$ ideal do governante letrado, alinhado aos valores dos studia humanitatis, encontrara na biblioteca espaço privilegiado para sua sustentação. A escolha das obras, tanto em forma quanto em conteúdo, não era um exercício aleatório; ao contrário, caracterizava-se por uma ação estrategicamente orientada para o fortalecimento de seu status social. Nesse sentido, Apício integraria o mobiliário daqueles studioli não por suas receitas - que de fato não despertaram o apetite do público renascentista ${ }^{40}$ - mas por seu valor simbólico. Os poucos leitores que o procuraram nesse momento, o fizeram muito provavelmente por motivos linguísticos bastante peculiares, como era o caso de humanistas como Teodoro Gaza (c. 1398-c. 1475), Antonio Beccadelli, o Panormita (1394-1471) e Giovanni Aurispa (1376-c. 1459) interessados no estudo de formas antigas do latim e do grego. ${ }^{41}$ Além disso lou por causa disso), o manuscrito parece não ter circulado.

\section{Estudo privado}

Um segundo momento da trajetória do manuscrito teria início com o governo de Lorenzo, o Magnífico, em 1469, e terminaria com sua colocação definitiva nos bancos do edifício construído especialmente para abrigar a Biblioteca Medicea Laurenziana em
35. De acordo com Ullman e Stadter (1972, p. 6): "The canon, a list of desiderata for a library is very comprehensive for the religious works, and especially in its listing of the writings of the fathers, often absent from medieval convent libraries. The choice of classical secular authors is vey general: the future pope lists a few authors but his general rule is to have as many classical writers and works as possible". Para o debate sobre as noções fundantes que organizam o Cânone Bibliográfico, cf. também Manfredi (1994, 1998).

36. Uma recente edição do Cânone Bibliográfico pode ser encontrada em Blasio, Roselli e Lelj (1984, p. 132-155).

37. Cf. nota 4 .

38. Cf. Milham (1967).

39. Este é talvez o mais célebre dos exemplares da tradição manuscrita de Apício. Foi recentemente digitalizado e pode ser visualizado em https://bit. ly/2OJ1gVU.

40. Essa e outras ideias são discutidas de maneira preliminar em Asfora Nadler (2016).

41. Tal interesse pode ser rastreado por meio da correspondência trocada em 1455 entre Giovanni Aurispa e o Panormita (Biblioteca Apostólica Vaticana, Vat. Ott. Lat. 1153, f. 25; Vat. Lat. 3772, f. 14 apud Sabbadini, 1931, p. 39-141). 
42. Ciapelli (2001, p. 43334).

43. Comanducci (2014, p. 261-265).

44. Poliziano (1553, p. 469).

45. Cf. Biblioteca Apostólica Vaticana (1494).

46. A suspeita de plágio, ainda não de todo consenso entre especialistas, assenta-se na comparação entre os colofões do manuscrito de Lorenzi e de Poliziano, que de fato são bastante semelhantes. Sobre a polêmica, cf. Fortuna (1999) e Savino (2013).

47. Cf. Beroaldo (1494).
1571. Embora Apício permanecesse parte da Medicea Privata, o papel de tesouro parece se atenuar em favor de um novo uso, rastreado direta e indiretamente por menções ao texto apiciano nos escritos de humanistas do período. Nesses 77 anos, a obra deixou o studiolo várias vezes para circular (ainda que de forma restrita) e peregrinar por diferentes espaços de armazenamento. Trata-se de um momento que precisa ser melhor estudado, mas sobre o qual algumas ideias podem ser lançadas.

Com Lorenzo de Médici a coleção abriu-se a um número cada vez maior de estudiosos. ${ }^{42}$ Obviamente, por não se tratar de uma coleção pública na essência do termo, seu acesso devia ser intermediado e chancelado pela rede de contatos da família. O conhecimento potencialmente oferecido pelo texło apiciano parecia chamar a atenção de um número de humanistas com interesses que iam além da filologia grega e latina. É desse período, por exemplo, o já mencionado registro de empréstimo a Bernardo Rucellai. O humanista que alguns anos depois promoverá encontros da Academia Platônica nos jardins de sua residência, os chamados Orti Oricellari, era um admirador incondicional da antiga Roma. Difícil saber se Rucellai pedira o códice motivado por Apício ou pela Germânia de Tácito, já que referências à história de Roma guiaram vários aspectos de sua vida pública e privada (desde a escolha arquitetônica e paisagística dos jardins ao melhor sistema político defendido para o governo de Florença). ${ }^{43}$

Se o interesse de Bernardo Rucellai por Apício é uma suposição, o mesmo não pode ser dito de seus contemporâneos. $\bigcirc$ humanista polímata Ângelo Poliziano (1454-1494), por exemplo, estudou atentamente o texto apiciano consultando não só o manuscrito laurenziano, mas também dois exemplares altomedievais com o objetivo de produzir ele próprio a sua cópia de Apício (o manuscrito São Petersburgo, no Instituta Istorii Akademii Nauk 627/2, hoje em fragmentos). Além disso, Poliziano usou também informações sobre Apício no seu Panepistemon - preâmbulo à lição sobre a Ética a Nicômaco de Aristóteles lida em 1490 no Studio Fiorentino. ${ }^{44} \mathrm{O}$ médico humanista florentino Lorenzo Lorenzi (1459/60-1502) é outro nome a ser lembrado. Assim como Poliziano, Lorenzi produziu igualmente uma cópia de Apício Ino manuscrito Vat. Lat. 6337), ${ }^{45}$ embora haja suspeitas de que essa tenha sido plágio de Poliziano e não fruto de um trabalho próprio de estudo e colação dos manuscritos altomedievais e do manuscrito laurenizano. ${ }^{46}$ Por último, há Filippo Beroaldo, o Velho (1453-1505), humanista que acessou o texto de Apício em busca de informações para seu estudo histórico-etimológico sobre termos citados no De re rustica de Columella (Enarrationes vocum priscarum in libris De re rustica). ${ }^{47}$

$\bigcirc$ que Poliziano, Lorenzi e Beroaldo foram buscar em Apício estava relacionado de alguma forma com subsídios para ampliar, debater ou rebater conhecimentos sobre a materia medica. A releitura de textos antigos $-e$, em alguns 
casos, a leitura pela primeira vez de textos nunca antes traduzidos para o latim abrira um novo espaço de reflexão sobre diversos campos do saber, dentre eles a medicina e a história natural. Em particular, Apício parece ter circulado dentre aqueles que de algum modo estavam relacionados com o movimento que se convencionou chamar de humanismo médico, cuja agenda, dentre outras coisas, incluía a discussão de nomes e atributos de plantas, animais e minerais a partir do cotejamento de um corpus de fontes antigas e contemporâneas cada vez mais vasto. ${ }^{48}$ Um uso diverso para Apício iria se configurar, portanto, nesse novo contexto intelectual; a obra deixaria seus atributos simbólicos em segundo plano para ganhar destaque pela possibilidade de estudo proporcionada por seus conteúdos sobre natureza. Apício fornecia uma espécie de catálogo da natureza conhecida na Antiguidade, sobre o qual interessava particularmente a listagem de plantas, sua descrição, propriedades e usos terapêuticos. ${ }^{49}$

Essas afirmações são possíveis para o período anterior à expulsão dos Médici de Florença, em 1494. Embora a pesquisa sobre a itinerância de Apício de 1495 a 1571 não esteja concluída, alguns dados sobre a lógica que organizou seu armazenamento e classificação ao longo daqueles anos oferecem pistas no sentido da continuidade de uma leitura pela perspectiva médica antiga, mais especificamente pela materia medica, como já adiantamos. $\bigcirc$ alinhamento de Apício com a medicina pode ser observado de forma efetiva pela opção de ordenação dos livros dos Médici nas caixas que os levaram para a Signoria e para - Convento de San Marco. Segundo o inventário de 1495, Apício, nº 618 , é seguido pela Mulomedicina de Vegécio (n 619 ) e pelos Aforismos de Hipócrates (n 620). Integrava, como sabemos pela cor da encadernação (verde nesse momentol, a seção dos livros de artes, à qual pertenciam também obras sobre agricultura e artes militares. ${ }^{50}$ Alguns anos depois, quando a coleção chegou a Roma, em 1508, os códices foram organizados em estantes dentro de seis armários. Apício recebeu número 381 e estava no sétimo armário, destinado aos textos de medicina, geografia, direito, filosofia. ${ }^{51}$ Retornados à Florença, os livros permaneceram durante cinquenta anos (de 1521 a 1571) em caixas, que muito provavelmente respeitavam os mesmos critérios de ordenamento.

\section{Estudo aberto}

A suposição anterior está baseada no fato de Apício ter permanecido na coleção médica até o início do século XX, quando o acervo da Biblioteca Medicea Laurenziana foi transferido da biblioteca monumental para seu
48. Cf. Pesenti (1999).

\begin{abstract}
49. Uma investigação aprofundada do uso médico de Apício é objeto central do projeto em andamento na Unicamp. No entanto, algumas reflexões preliminares podem ser encontradas em Asfora Nadler (2016).
\end{abstract}

50. Os livros da coleção possuíam encadernações com cores correspondentes às matérias das quais faziam parte: obras sacras, em azul; gramática, em amarelo; poéticas em roxo; artes, em verde; filosofia, em branco (Piccolomini, 1875, p. 115-119.)

51. "381. Apitii Caelii Epimeles De re coquinaria libri X; Caii Cornelii Taciti, equitis Romani, De situ et moribus Germaniae; liber Francisci Arretini, ad Pium ii pontificem, Diogenis epistolarum e graeco tralatio cum praefatione et [elegia] committit, Musa rogans uti hanc suam tralationem pontifici deferat ad Vaticanum." (Rao, 2012, p. 42). 
52. Cf. Asfora (2014).

53. Cf. Bernhold (1705, 1787).

54. Cf. Laurioux (1992).

55. Na atualidade, a documentação à qual o pesquisador tem acesso não permite rastrear com precisão os locais originais de armazenamento dos livros de cozinha manuscritos ao longo da Idade Média e do Renascimento. É possível especular que, por terem sido concebidos por mestres de cozinha para orientar preparações culinárias, estiveram em algum momento fisicamente presentes nas cozinhas de casas senhoriais. Quando as receitas desses manuscritos deixaram de ser instrumentos para o trabalho de cozinheiros, imagina-se que foram transferidos para outros locais de guarda, inclusive bibliotecas. Situação um pouco distinta é aquela dos primeiros livros de cozinha impressos, que, ao que tudo indica, respondiam a um crescente interesse pelo conhecimento específico sobre alimentos (e suas preparações), dissociando-os de outros elementos componentes do programa dietético da antiga medicina ainda vigente, como banhos, atividades físicas e conduta de vida. Cf. Laurioux (2006); Nicoud (2007); Notaker (2012). espaço atual. Nesse terceiro momento da trajetória do manuscrito, a lógica de classificação de Apício como texto médico teria se mantido. Acorrentado deliberadamente em um banco destinado a textos médicos da Antiguidade e da Idade Média latina, Apício compunha um conjunto de fontes, ou de autoridades, como queiramos, parte do patrimônio médico latino que, a partir de 1571, estava disponível de maneira mais aberta para qualquer estudioso, sem a intermediação de antigos proprietários.

Um olhar mais alargado para a classificação dada a Apício pela biblioteca pública fundada pelos Médici evidencia alinhamento com a leitura que dele era feita desde a Alta Idade Média, pelo menos. Dos três manuscritos medievais existentes, um pertenceu a um códice médico que continha, além de Apício, um texto de tradição hipocrática sobre dieta (De observantia ciboruml e um receituário médico anônimo. ${ }^{52}$ Tal alinhamento é percebido igualmente na opção de obras publicadas conjuntamente com Apício na edição de 1541, que traz, além do texło apiciano, o tratado médico-filosófico De honesta voluptate et valetudine, de Platina, e De facultatibus alimentorum, do médico bizantino Paulo de Égina. Outro indício é o perfil do editorcomentador do texto apiciano na edição de 1542, o médico alemão Gabriel Hummelberg. Poderíamos ir ainda mais distante no tempo ao lembrar as duas únicas edições conhecidas de Apício do século XVIII - ambas organizadas e comentadas por médicos. ${ }^{53}$

Ademais, outro elemento parece reforçar essa perspectiva médica para Apício. Como dito anteriormente, a comida que resultava das receitas apicianas não estava em consonância com o gosto vigente no Renascimento (nem mesmo com aquele que se conseguiu rastrear a partir dos séculos XIII e XIV54) e, por esse motivo, seria mais fácil dissociá-lo de livros de cozinha produzidos no período e deslocá-lo para espaços frequentados por homens das letras, como studioli e bibliotecas. ${ }^{55}$ Ao perder seu sentido original, o livro de cozinha romano recebe nova chancela que o autoriza a ser usado como fonte de outro tipo de saber que não o do ofício de cozinhar. Nunca é demais lembrar que, do ponto de vista da tradição intelectual ocidental, as artes culinárias não constituíam um saber valorizado a ponto de ocuparem lugar legítimo dentre as sete artes liberais. No caso de Apício, a chancela vem dos humanistas médicos que passam a enxergar o conteúdo da obra não mais como uma compilação de ingredientes e modos de fazer comida, mas como uma espécie de glossário de plantas, animais e minerais em uso no mundo antigo que poderiam auxiliálos naquele momento no estudo da materia medica. 


\section{CONSIDERAÇÕES FINAIS}

Os aspectos que destacamos na trajetória do manuscrito de Apício Plut. 73.20 são pontuais, mas permitem desenvolver algumas reflexões finais lainda que provisórias) sobre sentido e consumo do texto apiciano no Renascimento.

Primeiramente, teria existido dois tipos de consumo para Apício ao longo de sua existência entre os séculos XV e XVI. Até mais ou menos a década de 1470, quando o livro se achava confinado ao espaço restrito do studiolo, teria havido um consumo ostentatório de Apício como objeto de luxo e não propriamente em função do conteúdo de suas receitas. Em um momento seguinte, essa perspectiva do livroobjeto teria sido deixada de lado para dar lugar a outra, que privilegiaria o conteúdo daquelas receitas como veículo de conhecimento. Ou seja, as receitas passaram a ser vistas como fonte para estudo da materia medica - deviam ser entendidas dentro do contexto intelectual do humanismo médico, cada vez mais engajado no estudo dos antigos textos sobre qualquer aspecto da natureza que pudesse colaborar para o desenvolvimento da medicina do período. Esse viés de leitura de Apício teria sido impulsionado pela abertura da coleção pessoal dos Médici aos intelectuais nele interessados - inicialmente de modo restrito, pois o acesso só seria garantido mediante permissão de seus proprietários, mas posteriormente de modo irrestrito com a colocação definitiva do acervo em uma biblioteca pública. É muito provável que Apício como livro-objeto continuasse a despertar interesse por seus atributos materiais refinados e pelo seu potencial simbólico; no entanto, pensamos que quando a obra passa a circular entre os humanistas é a perspectiva de conhecimento que irá ganhar proeminência.

Sugerir que Apício teria sido um texto que se prestava ao estudo da materia medica não é um dado isolado, exclusivo à história do manuscrito laurenziano. Bem ao contrário, como procuramos indicar, essa noção parece ser herdada da Idade Média e compartilhada pelo grupo de intelectuais que de alguma maneira se interessaram e se apropriaram do texto no Renascimento, norteados por demandas próprias ao humanismo renascentista da Itália e posteriormente do norte da Europa, como o estudo dos demais manuscritos e edições parece anunciar. Essas afirmações manifestam a necessidade de um olhar mais profundo para a questão que de fato subjaz o suposto estranhamento de Apício pertencer a uma categoria que não a culinária: a necessidade de pensar com mais atenção sobre os sistemas de ordenação dos saberes antigos e medievais e sua relação com as classificações modernas das ciências. Apício nos faz questionar onde estaria o ponto de inflexão das categorias "médico" e 
56. Meneses (1983, p. 113). "culinário", que já foram usadas para classificá-lo - e, mais precisamente, nos faz pensar sobre o papel do processo de racionalização que organizou o pensamento científico moderno a partir do século XVIII no posicionamento do conteúdo de sua obra dentro ou fora de dado universo do saber.

Por fim, parece-nos importante retomar a proposta teórica de Ulpiano Bezerra de Meneses a fim de dissipar uma possível leitura enviesada do Plut. 73.20 apenas como produto cultural. Queremos com isso dizer que há dinamismo na forma como entendemos a existência e trajetória do manuscrito. Sem dúvida os atributos físicos que o caracterizam como objeto o revelam como resultante do ímpeto que na metade do século XV moveu intelectuais em direção à (re)descoberta e emulação do conhecimento oriundo de textos antigos. Contudo, o manuscrito em sua concretude exerceu também papel de vetor que canalizou o impulso e a demanda advindos de determinado grupo social por certo tipo de conhecimento na época: os humanistas médicos, em sua busca pela natureza e materia medica antiga. ${ }^{56}$ Em outras palavras, trata-se de compreender o manuscrito inserido no dinamismo do tecido social ao qual pertenceu e por onde circulou.

\section{REFERÊNCIAS}

\section{FONTES MANUSCRITAS}

BIBLIOTECA APOSTÓliCA VATICANA. Vat. Lat. 6337. Cidade do Vaticano, 1494. Disponível em: <https://bit.ly/2w9ztX1>. Acesso em: 16 ago. 2018.

Urb. Lat. 1146. Cidade do Vaticano, 830-853. Disponível em: <https://bit.ly/2OJ1gVU>. Acesso em: 17 ago. 2018.

Urb. Lat. 1145. Cidade do Vaticano, [14--]a. Disponível em: <https://bit.ly/2MwBHdg>. Acesso em: 20 ago. 2018.

Vat. Lat. 6803. Cidade do Vaticano, [14--]b. Disponível em: <https://bit.ly/2vV7bAa>. Acesso em: 20 ago. 2018. 
Vat. Lat. 8086. Cidade do Vaticano, 1483-1489. Disponível em: <https://bit. ly/2PmQFRR>. Acesso em: 20 ago. 2018.

BIBLIOTECA ESTENSE UNIVERSITARIA. Lat. 134=alfa.R..9.5. Modena, [14--]. Disponível em: <https://bit.ly/2vXAQJ1>. Acesso em: 20 ago. 2018.

BIBLIOTECA MEDICEA LAURENZIANA. Plut. 73.20. Florença, 1458-1464. Disponível em: $<$ https://bit.ly/2MsPgvm>. Acesso em: 16 ago. 2018.

BIBLIOTHÈQUE NATIONALE DE FRANCE. Département des Manuscrits, Archives Modernes. Latin 10318. Paris, [7--?]. 289 f. (Anthologie Latine). Disponível em: <https://bit.ly/2MxCtqv>. Acesso em: 16 ago. 2018.

\section{FONTES IMPRESSAS}

ANDRÉ, Jacques (Ed.). Apicius: l'art culinaire. Paris: Le Belles Lettres, 1987.

BERNHOLD, Joannes Michael. Apicii Coelii de opsoniis et condimentis, sive arte coquinaria libri $X$. Cum annotationibus Martini Lister et notis selectioribus, variisque lectionibus integris Gabrielis Humelbergii, Casparis Barthii et variorum. London: Bowyer, 1705.

Caeli Apicii De opsoniis et condimentis; sive, Arte coquinaria, libri X. Cum lectionibus variis atque indice, [Markbreit, J. V. Knenlein], 1787.

BEROALDO, O Velho, Filippo. Enarrationes vocum priscarum in libris De re rustica. In: COLUCIA, Franciscus; MERULA, Georgius; BEROALDUS, Philippus. [Scriptores rei rusticate]... Bolonha: Benedictus Hectoris, 1494. Disponível em: <https://bit.ly/2Pg1vcb>. Acesso em: 16 ago. 2018.

GRAINGER, Sally; Christopher GROCOCK (Eds.). Apicius. Totnes: Prospect, 2006.

HUMMELBERG, Gabriel (Ed.). Apicii Caelii De opsonis et condimentis, sive arte coquinaria. Libri X. Zurique: [s.n.], 1542.

POLIZIANO, Angelo. Opera. Basel: Nicolaus Episcopus, 1553.

RICORDI di arienti, libri et altre cose prestate, cominciato questo dì 30 di maggio 1480. In: PIAZZO, Marcello del (Ed.). Protocolli del Carteggio di Lorenzo il Magnifico per gli anni 147374, 1477-1492. Firenze: Leo. S. Olschki, 1956. p. 227-228. 
ROTHMAGENSEM, Guilermun Signerre (Ed.). Apicius in re quoquinaria. Milão: [s.n.], 1498.

SABBADINI, Remigio (Ed.). Carteggio di Aurispa. Roma: Tipografia del Senato, 1931.

TACUINUM, Cereto de Tridino alias (Ed.). Apitii Celii De re coquinaria: libri decem. Veneza: [s.n.], 1503.

TORINUS, Albano (Ed.). Caelii Apitii summi adulatricis De re culinaria. Libri X. Basiléia: [s.n.], 1541.

VENETUM, Bernadium (Ed.). Apitii Celii De re coquinaria libri decem. Veneza: [s.n.], 1500.

\section{LIVROS, ARTIGOS E TESES}

AMES-LEWIS, Francis. The Inventories of Piero de Cosimo de Medici's Library. La Bibliofilia, Florença, v. 84, p. 103-142, 1982.

ASFORA NADLER, Wanessa. Apício como opus medicinale na Itália do século XV: estudo de caso a partir de três manuscritos fiorentinos”. In: Soares, Carmen; Ribeiro, Cilene (Eds.). Mesas luso-brasileiras: alimentação, saúde E cultura. Curitiba: Champagnat; Coimbra: Imprensa da Universidade de Coimbra, 2018. v. 1. No prelo.

Collecting and Interpreting Apicius in $15^{\text {th }}$-century Italy: manuscript tradition and circulation of culinary/dietary knowledge. FoodEHistory, Turnhout, v. 14, nºs. 2-3 (2016), pp. 183-203.

ASFORA, Wanessa. Apício: história da incorporação de um livro de cozinha na Alta Idade Média. São Paulo: Alameda, 2014.

BANDINI, Angelo Maria. Catalogus codicum Latinorum Bibliothecae Mediceae Laurentianae. Florença: [s.n.], 1774-1777. v. 1-4.

BILABEL, Friedrich (Ed.). Opsartytika und Verwandtes. Heidelberg: Carl Winters Universitatsbuchhandlung, 1920.

BLASIO, Maria Grazia; ROSELLI, Giuseppe; LELJ, Caterina. Un contributo alla lettura del canone bibliografico di Tomaso Parentucelli. Città del Vaticano: Scuola Vaticana di Paleografia, Diplomatica re Archivistica, 1984. 
BOUZA-ÁlVAREZ, Fernando. Corre manuscrito: una historia cultural del Siglo de Oro. Madrid: Marcial Pons, 2001.

BURKE, Peter. A invenção da biografia e o individualismo renascentista. Revista de Estudos Históricos, Rio de Janeiro, v. 10, n. 19, p. 83-97, 1997.

The European Renaissance: Centre and Peripheries. Oxford: Blackwell, 1998.

CAVALLO, Guglielmo. Libri, editori e pubblico nel mondo antico: guida storica e critica. Roma: Laterza, 1989.

I luoghi della memoria scritta: manoscritti, incunaboli, libri a stampa de Biblioteche Statali. Roma: Istituto Poligrafico/Libreria dello Stato, 1994.

CHARTIER, Roger. Culture écrite et société l'ordre des livres, XIVe-XVIIIe siècle. Paris: A. Michel, 1996.

Inscrever e apagar: cultura escrita e literatura (séculos XI-XVIII). São Paulo: Editora Unesp, 2007.

Práticas da leitura. São Paulo: Estação Liberdade, 2009.

CIAPELLI, Giovanni. Biblioteche e lettura a Firenze nel Quattrocento. Alcune considerazioni. In: LOMBARDI, Giuseppe; NEBIAI-DALLA GUARDA, Donatella (Ed.). Libri, lettori e biblioteche dell'Italia medievale (secolo $I X-X V$ ): fonti, testi, utilizzazione del libro. Atti della Tavola rotonda ítalo-francese (Roma 7-8 marzo, 1997). Paris: CNRS; Roma: ICCU, 2001. p. 425-439.

CLARK, Leah. Collecting, exchange, and sociability in the Renaissance studiolo. Journal of the History of Collections, Oxford, v. 25, n. 2, p. 171-184, 2013.

COMANDUCCI, Rita Maria. Orti Oricellari. In: ISTITUTO DELLA ENCICLOPEDIA ITALIANA. Enciclopedia Machiavelliana. Roma, 2014. v. 2, p. 261-265.

DE LA MARE, Albinia. Cosimo and His Books. In: AMES-LEWIS, Francis (Ed.). Cosimo il Vecchio de Medici (1389-1464). Oxford: Clarendon Press, 1992. p. 115-156.

. Vespasiano da Bisticci as producer of Classical Manuscripts in Fifteenth-Century Florence. In: CHAVANNES-MAZEL, Claudine; SMITH, Margareth (Eds.). Medieval Manuscripts of the Latin Classics: production and use. Los Altos Hills: Anderson-Lovelace, 1996. p. 167-207.

DE LA MARE, Albinia; GARZELLI, Annarosa (Eds.). Miniatura fiorentina del Rinascimento (14401525): un primo censimento. Firenze: La Nuova Italia; Giunta Regionale Toscana, 1985. v. I. 
FEBVRE, Lucien; MARTIN, Henry-Jean. O aparecimento do livro. Tradução: Fulvia M. L Moretto e Guacira Marcondes Machado. São Paulo: Unesp/Hucitec, 1992.

FORTUNA, Stefania. Le prime traduzioni umanistiche degli aforismi di Ippocrate. In: GAROFALO, Ivan et al. (Eds). Aspetti della terapia nel Corpus Hippocraticum: Atti del IXe Colloque Internationale Hippocratique. Florença: L. S. Olschki, 1999. p. 485-498.

LAURIOUX, Bruno. Idade Média à mesa. Tradução: Elsa Andringa. Lisboa: Publicações Europa-América, 1992.

Gastronomie, humanisme et société à Rome au milieu du XVe siècle. Firenze: Sismel/ Edizione del Galuzzo, 2006.

MANFREDI, Antonio. I codici latini di Niccolò V: edizione degli inventari e identificazione dei manoscritto. Città del Vaticano: Biblioteca Apostolica Vaticana, 1994.

The Vatican Library of Pope Nicholas V: the Project of a Universal Library in the age of Humanism. Library History, Londres, v. 4, p. 103-110, 1998.

MENESES, Ulpiano T. Bezerra. A cultura material no estudo das sociedades antigas. Revista de História, São Paulo, n. 115, p. 103-117, 1983.

MILHAM, Mary Ella. Toward a stemma and fortuna of Apicius: Italia Medioevale e Umanistica. v. 10. Padova: Antenore, 1967. p. 259-320

NICOUD, Marilyn. Les régimes de santé au Moyen Âge: naissance et diffusion d'une écriture médicale en Italie et en France (XIIIe- XVe). Rome: École Française de Rome, 2007. 2 v.

NOTAKER, Henry. Printed Cookbooks: food history, book history, and literature, FoodEHistory, Turnhout, v. 10, n. 2, p. 131-159, 2012.

PESENTI, Tiziana. Annotazioni sull'umanesimo medico. Quaderni per la storia della Università di Padova, Roma/Padova, v. 32, p. 249-259, 1999.

PICCOLOMINI, Enea. Intorno alle condizioni ed allte vicende della Libreria Medicea Privata. Richerche di Enea Piccolomini. Firenze: Cellini, 1875.

PINTOR, Fortunato. Per la storia della libreria medicea nel Rinascimento: appunti d'archivio. Italia Medioevale e Umanistica, Roma/Padova, v. 3, p. 188-210, 1960.

RAO, Ida Giovanna. L'inventario di Fabio Vigili della Medicea Privata. Città del Vaticano: Biblioteca Apostolica Vaticana, 2012. 
SAVINO, Cristina. La traduzione di Lorenzo Lorenzi del Commento di Galeno agli Aforismi di Ippocrate: un caso di plagio? Medicina nei Secoli, Roma, v. 25, n. 3, p. 1023-1062, 2013.

STAM, David (Ed.). International Dictionary of Library Histories. Chicago/London: Fitzroy Dearborn, 2001.

ULLMAN, Berthold; STADTER, Phillip. The Public Library of Renaissance Florence. Roma/ Padova: Antenore, 1972.

Artigo apresentado em $01 / 02 / 2018$. Aprovado em 27/07/2018.

All the contents of this journal, except where otherwise noted, is licensed under a Creative Commons Attribution License

\section{(cc) BY}

